\title{
FNR-dependent repression of $n d h$ gene expression requires two upstream FNR-binding sites
}

\author{
Wenmao Meng, Jeffrey Green and John R. Guest
}

The Krebs Institute for Biomolecular Research, Department of Molecular Biology \& Biotechnology, University of Sheffield, Firth Court, Western Bank, Sheffield S10 2TN, UK
Author for correspondence: John R. Guest. Tel: +44 114 2224403/6. Fax: +44 1142728697. e-mail: j.r.guest@sheffield.ac.uk

The ndh gene of Escherichia coli encodes a non-proton-translocating NADH dehydrogenase (NdhII) that is anaerobically repressed by the global transcription regulator, FNR. FNR binds at two sites (centred at $\mathbf{- 5 0 . 5}$ and -94.5) in the ndh promoter but the mechanism of FNR-mediated repression appears not to be due to promoter occlusion. This mechanism has been investigated using an aerobically active derivative of FNR, FNR* (FNR-D154A), with ndh promoters containing altered FNR-binding sites. FNR* repressed $n d h$ gene expression both aerobically and anaerobically in vivo. Gel retardation analysis and DNase I footprinting with purified FNR* protein confirmed that FNR interacts at two sites in the ndh promoter, and that FNR and RNA polymerase (RNAP) can bind simultaneously. Studies with three altered ndh promoters, each containing an impaired or improved FNR-site, indicated that both FNR-sites are needed for efficient repression in vivo. The $\alpha$-subunit of RNAP interacted with two regions (centred at -105 and -46), each overlapping one of the FNR-sites in the ndh promoter. Footprints of the FNR*-RNAP-ndh ternary complex indicated that FNR ${ }^{*}$-binding at -50.5 prevents the $\alpha$-subunit of RNAP from docking with the DNA just upstream of the -35 element. Binding of a second FNR* molecule at the -105 site likewise prevents binding of the $\alpha$-subunit at its alternative site, thus providing a plausible mechanism for FNR-mediated repression based on displacement of the $\alpha$-subunit of RNAP.

Keywords: NADH dehydrogenase II, FNR, RNA polymerase, transcription regulation, Escherichia coli

\section{INTRODUCTION}

The facultative anaerobe Escherichia coli possesses two NADH dehydrogenases, NdhI and NdhII, which serve as primary dehydrogenases in the aerobic respiratory chain (Calhoun \& Gennis, 1993; Calhoun et al., 1993). NdhI, encoded by the nuo operon, is a multi-subunit, membrane-bound, proton-translocating enzyme similar to mitochondrial Complex I (Weidner et al., 1992). NdhII, encoded by the $n d h$ gene, is a monomeric, membrane-associated, non-proton-translocating flavoprotein (Young et al., 1981; Matsushita et al., 1987; Hayashi et al., 1989). The nuo operon and the ndh gene are both repressed by anaerobiosis, the former via the

Abbreviations: CRP, CAMP receptor protein; FNR, regulator of fumarate and nitrate reduction; GST, glutathione S-transferase; NdhI (NdhII), NADH dehydrogenase I (II); Pndh, ndh gene promoter region; RNAP, RNA polymerase; $\alpha_{C \mathrm{CD}}$ C-terminal domain of the $\alpha$-subunit of RNA polymerase.
ArcB-A two-component sensor-regulator system (Bongaerts et al., 1995) and the latter via FNR (Spiro et al., 1989).

FNR is a global transcription regulator which activates or represses the expression of target genes in response to anaerobiosis. Its response is mediated by the anaerobic acquisition of a [4Fe-4S] centre leading to dimerization, enhanced binding to the FNR operator sequence (TTGAT----ATCAA) and consequent regulation of transcription (Khoroshilova et al., 1995; Green et al., 1996a, b; Lazazzera et al., 1996). It has also been suggested that FNR normally exists as a monomer in vivo and that it only dimerizes on its target DNA (Melville \& Gunsalus, 1996). FNR activates transcription by binding to a site centred at about -41 in target promoters where it makes direct activating contacts with RNA polymerase (RNAP) (Bell \& Busby, 1994). The mechanism of FNR-mediated repression is less well 
(a)

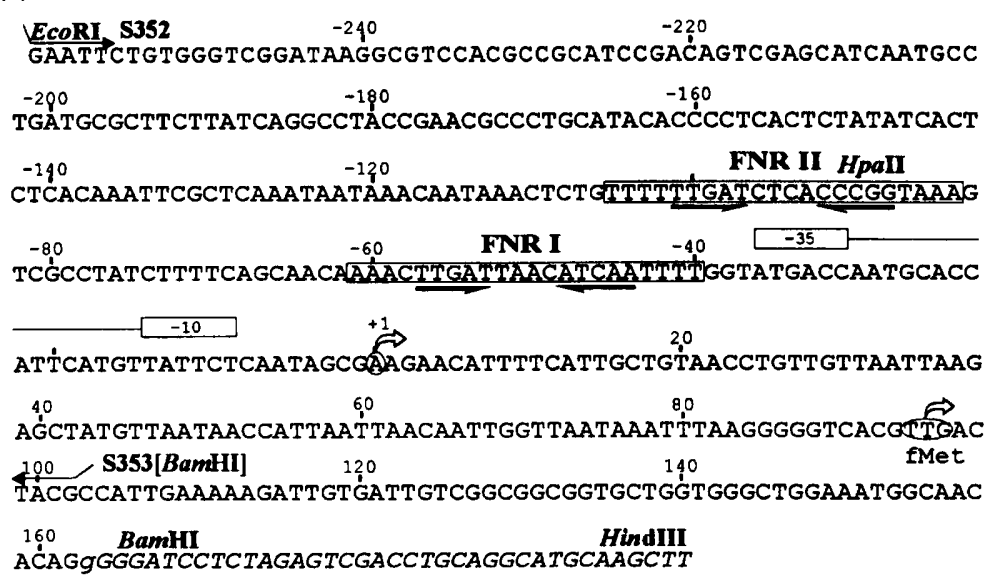

(b)

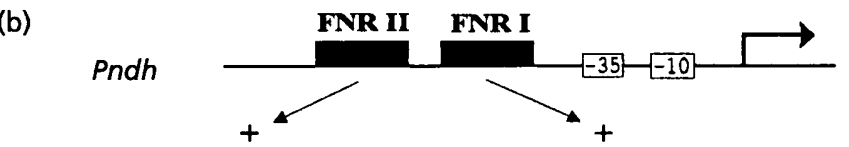

(i)

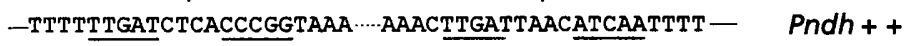

(ii)

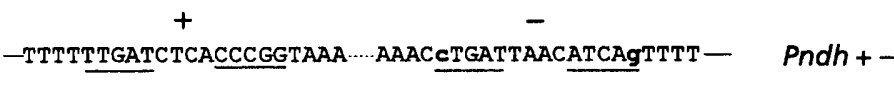

(iii)

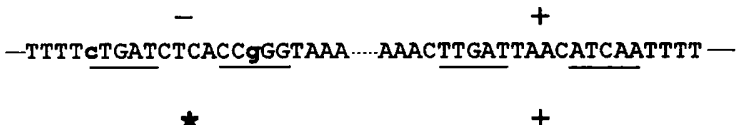

(iv) -TTTTTTGATCTCAatCaaTAAA …AAACTTGATTAACATCAATTTT -
Pndh-+

Pndh*+
Fig. 1. Nucleotide sequence and mutagenesis of the $n d h$ promoter of $E$. coli. (a) Nucleotide sequence of the ndh promoter region of pGS418, including nucleotides from the vector (italicized), and showing: the FNR-sites, FNR I (-50.5) and FNR II (-94.5); the -35 and -10 hexamers; transcription and translation start points (open arrows above sequence); PCR primers; and relevant restriction sites. The lower case $g$ at the junction between insert and vector was found to be deleted. (b) Comparison of the nucleotide sequences of wild-type $(+)$, impaired (-) and improved (*) FNR-sites of wild-type and altered ndh promoters. Base substitutions are shown in bold lowercase letters. (i) Pndh ++ , wild-type; (ii) Pndh + - ; (iii) Pndh - + ; (iv) Pndh* +. defined. Repression of $n d b$ gene expression involves FNR-binding at two sites: a high-affinity site (FNR I; TTGAT----ATCAA) which is centred at -50.5 and contains a perfect match to the FNR-site consensus, and a low-affinity site (FNR II; TTGAT----ACCCG) which is centred further upstream at -94.5 and matches the consensus in only one half-site (Fig. 1; Sharrocks et al., 1991; Green \& Guest, 1994). The importance of FNR II was inferred from footprints of the $n d h$ promoter with site-directed FNR variants which are unable to repress $n d h$ expression in vivo (Sharrocks et al., 1990) but retain the capacity to protect FNR I but not FNR II (Green et al., 1993). The importance of FNR II was further emphasized by the reduction in $n d b$ promoter activity (in vivo) and in FNR-mediated repression (in vitro) that accompanies the deletion of this upstream site (Green \& Guest, 1994). Distant upstream FNR-sites have also been shown to be important for efficient repression of the $f n r$ and narX promoters (Takahashi $e t$ al., 1994).

In this work the mechanism of $n d h$ repression was investigated by a combination of in vivo and in vitro approaches using an aerobically active FNR variant, FNR* (Kiley \& Reznikoff, 1991; Lazazzera et al., 1993). FNR* greatly facilitated the use of most in vitro techniques by eliminating the need for anaerobic activation of the regulator. The results showed that both FNR-sites are required for full repression of $n d b$ gene expression and that repression is not simply due to promoter occlusion but to an FNR-mediated displacement of the $\alpha$-subunit of RNAP.

\section{METHODS}

Bacterial strains, plasmids and phages. The strains of $E$. coli, plasmids and phages are listed in Table 1 . Strain DH5 $\alpha$ was the host for propagating plasmids, JRG3462 was the source of glutathione $S$-transferase (GST)-FNR * fusion protein, RK5279 was the $\beta$-galactosidase null strain used for assaying $n d b-$ lacZ fusion activities, and BW313 was used for producing uracil-containing DNA. The $f n r^{*}$ gene was transferred from pFNRDA154 (kindly provided by S. J. W. Busby, University of Birmingham, UK) to pUC19 and pBR328 as a 1.64 HindIII$B a m H I$ fragment, and the $f n r^{*}$ mutation was transferred to the coding region of the expression plasmid pGS771 (Fig. 2a) by PCR amplification of an $f n r^{*}$ fragment and reconstruction of the intact and resequenced $f n r^{*}$ gene in a $1156 \mathrm{bp}$ Ncol-HindIII fragment that was subsequently cloned in pGEX-KG. The primary source of $n d h$ promoter DNA was pGS418 (Green \& Guest, 1994). A derivative of pALTEREX1, pGS828, containing the 430 bp EcoRI-BamHI, ndh promoter $(P n d h)$ fragment from pGS418, was used to create three altered $n d h$ promoters (Fig. 1b), Pndh +- (FNR-Iimpaired), Pndh - + (FNR-II-impaired) and Pndh*+ (FNRII-improved), first as pGS828 derivatives (pGS829-pGS831, respectively) and then as pUC18 derivatives (pGS832-pGS834) by inserting the EcoRI-BamHI promoter fragments, in order to create plasmids that are directly analogous to pGS418 
Table 1. Strains of $E$. coli and plasmids

\begin{tabular}{|c|c|c|}
\hline $\begin{array}{l}\text { Strain or } \\
\text { plasmid }\end{array}$ & Genotype or relevant features & Source or reference \\
\hline \multicolumn{3}{|l|}{ E. coli } \\
\hline DH5 $\alpha$ & $\Delta l a c U 169$ ( $(80 l a c Z \Delta M 15)$ supE44 hsdR17 recA endA1 gyrA96 thi-1 recA1 & Hanahan (1983) \\
\hline CAG627 & lac $Z_{a m} \operatorname{trp}_{a m} p h o_{a m} \sup C_{t s}$ ma lon $r p s L$ & Green et al. (1996b) \\
\hline JRG3462 & CAG627 transformed with pGS771 & This work \\
\hline RK5279 & $\Delta l a c U 169$ fnr-250 ara gyrA non $r p s L$ & $\begin{array}{l}\text { V. Stewart, Cornell } \\
\text { University, USA }\end{array}$ \\
\hline JRG1991 & $\lambda n d b-l a c Z$ ( $\lambda \mathrm{G} 211)$ lysogen of RK5279; $\mathrm{Ap}^{\mathrm{R}}$ & Spiro et al. (1989) \\
\hline BW313 & Hfr lys A thi relA dut ung & Kunkel et al. (1987) \\
\hline \multicolumn{3}{|l|}{ Plasmids } \\
\hline pGS24 & pBR322 derivative with $f n r$ gene in $1.64 \mathrm{~kb}$ HindIII-BamHI fragment; $\mathrm{Ap}^{\mathbf{R}}$ & Shaw \& Guest (1982) \\
\hline pFNRDA154 & $\begin{array}{l}\text { pGS24 with } f n r^{*} \text { gene in } 1.64 \mathrm{kd} \text { HindIII-BamHI fragment, no upstream/vector } \\
\text { EcoRI sites; } \mathrm{Ap}^{\mathrm{R}}\end{array}$ & $\begin{array}{l}\text { S. J. W. Busby, Birmingham } \\
\text { University, UK }\end{array}$ \\
\hline pGS336 & pUC19 with $f n r$ from pGS24; $\mathrm{Ap}^{\mathrm{R}}$ & Sharrocks et al. (1990) \\
\hline pGS388 & pBR328 with fnr from pGS24; $\mathrm{Cm}^{\mathrm{R}} \mathrm{Ap}^{\mathrm{R}}$ & Sharrocks et al. (1990) \\
\hline pGS998 & pUC19 with $f n r^{* t}$ from pFNRDA154; $\mathrm{Ap}^{\mathrm{R}}$ & This work \\
\hline pGS1009 & pBR328 with $f n r^{*}$ from pFNRDA154; $\mathrm{Cm}^{\mathrm{R}} \mathrm{Ap}^{\mathrm{R}}$ & This work \\
\hline pGEX-KG & GST-fusion vector; $A p^{R}$ & Guan \& Dixon (1991) \\
\hline pGS771 & $\begin{array}{l}\text { pGEX-KG derivative with reconstructed } f n r^{*} \text { in a } 1156 \text { bp Ncol-HindIII fragment; } \\
\text { Ap }^{\mathrm{R}}\end{array}$ & This work \\
\hline pGS418 & pUC18 with a 422 bp Pndh ++ fragment; Ap ${ }^{R}$ & Sharrocks et al. (1991) \\
\hline pALTER-EX1 & Vector for mutagenesis; $\mathrm{Tc}^{\mathrm{R}}$ & Promega \\
\hline pGS828 & $P n d h++$ in 430 bp EcoRI-BamHI fragment from pGS418 in pALTER-EX1; Tc ${ }^{\mathrm{R}}$ & This work \\
\hline pGS832 & $P n d h+-$ derivative of $\mathrm{pUC18} ; \mathrm{Ap}^{\mathrm{R}}$ & This work \\
\hline pGS833 & $P n d h-+$ derivative of $\mathrm{pUC18} ; \mathrm{Ap}^{\mathrm{R}}$ & This work \\
\hline pGS834 & $P n d b^{*}+$ derivative of $\mathrm{pUC18} ; \mathrm{Ap}^{\mathrm{R}}$ & This work \\
\hline pRW50 & lac $Z$ operon fusion vector & Lodge et al. (1992) \\
\hline pGS994 & $P n d h++$ in 367 bp EcoRI-BamHI fragment in pRW50; $\mathrm{Tc}^{\mathrm{R}}$ & This work \\
\hline pGS995 & $P n d h+-$ derivative of pGS994; $\mathrm{Tc}^{\mathrm{R}}$ & This work \\
\hline pGS996 & Pndh -+ derivative of pGS994; Tc ${ }^{R}$ & This work \\
\hline pGS997 & $P n d b^{*}+$ derivative of pGS994; $\mathrm{Tc}^{\mathrm{R}}$ & This work \\
\hline
\end{tabular}

(Table 1). The substitutions were confirmed by nucleotide sequencing at the intermediate stage. A corresponding set of Pndh-lacZ operon fusion plasmids (pGS994-pGS997) was constructed in a low-copy vector (pRW50, kindly provided by S. J. W. Busby) for investigating their regulation by FNR and FNR". Two synthetic primers, S352 (5'-TAGCTA GAATTCTGTGGGTCGGATAAGGCG-3') and S353 ( $5^{\prime}$-CGTGCATGGATC CGTAGTCAACGTGACCCCC- $3^{\prime}$ ), were used to PCRamplify four $367 \mathrm{bp} n d h$ promoter fragments flanked by EcoRI and BamHI sites (Fig. 1a), prior to subcloning in pRW50 and sequence confirmation (Table 1). An alternative approach, involving the construction of monolysogenic strains containing different $\lambda n d b-l a c Z$ translational fusions ( $\lambda \mathrm{G} 211$ ) by subcloning the altered EcoRI-BamHI fragments to the corresponding fusion vector and transfer to $\lambda R Z 5$ (Spiro et al., 1989), was attempted but failed. This ultimately proved to be due to a single $G$ deletion and consequent reading-frame shift that had occurred at a PvuII-SmaI junction during the construction of the parental plasmid, pGS418 (Fig. 1a). This probably explains why the $n d h-l a c Z$ translational fusions of two plasmids (pGS602 and pGS603) derived from pGS418 had very low activities (Green \& Guest, 1994).

Microbiological methods. Cultures were grown routinely at $37^{\circ} \mathrm{C}$ with vigorous shaking in L-broth with ampicillin $\left(100 \mu \mathrm{g} \mathrm{m}^{-1}\right)$, tetracycline $\left(35 \mu \mathrm{g} \mathrm{ml}^{-1}\right)$ or chloramphenicol $\left(10 \mu \mathrm{g} \mathrm{ml}^{-1}\right)$, as required. $\beta$-Galactosidase activities expressed from $n d b-l a c Z$ protein and operon fusions were assayed according to Miller (1972) using cultures grown in L-broth plus glucose $(0.4 \%)$, either aerobically or anaerobically (in screw-cap bottles filled to the neck). The quoted specific activities (in Miller units) are averages from duplicate samples of at least three independent cultures, variations being no more than $15 \%$ from the mean.

Protein amplification, purification and properties. The GSTFNR * fusion protein was amplified to $13 \%$ of soluble protein (equivalent to $5.5 \mathrm{mg} \mathrm{FNR*} \mathrm{per} \mathrm{litre} \mathrm{of} \mathrm{culture)} \mathrm{by} \mathrm{inducing}$ aerobic cultures of JRG3462 with IPTG $\left(30 \mu \mathrm{g} \mathrm{ml}^{-1}\right)$. It was purified aerobically from French press extracts (Fig. 2b) by chromatography on GSH-agarose (Sigma) and heparin agarose (Green et al., 1996b). The FNR* (FNR-D154A) protein was released by cleavage with thrombin (Sigma) and separated from GST by repeating the GSH-agarose step to give a product of $>95 \%$ purity, as judged by SDS-PAGE (Fig. 2b). This material contained up to 0.7 atoms $\mathrm{Fe}$ and 0.02 atoms acid-labile $S$ per monomer indicating that its $[4 \mathrm{Fe}-4 \mathrm{~S}]$ clusters had been degraded. The purified FNR* protein, stored at $4{ }^{\circ} \mathrm{C}$, was partially dimeric (Lazazzera et al., 1993), and had a fourfold higher affinity for target DNA in footprinting reactions than comparable samples of wild-type FNR. 
(a)

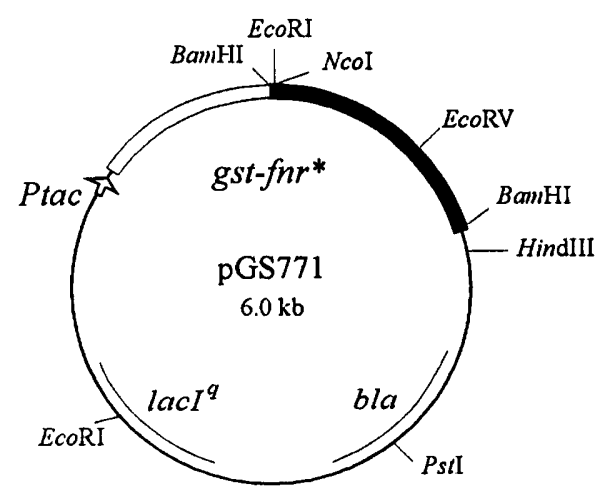

(b)

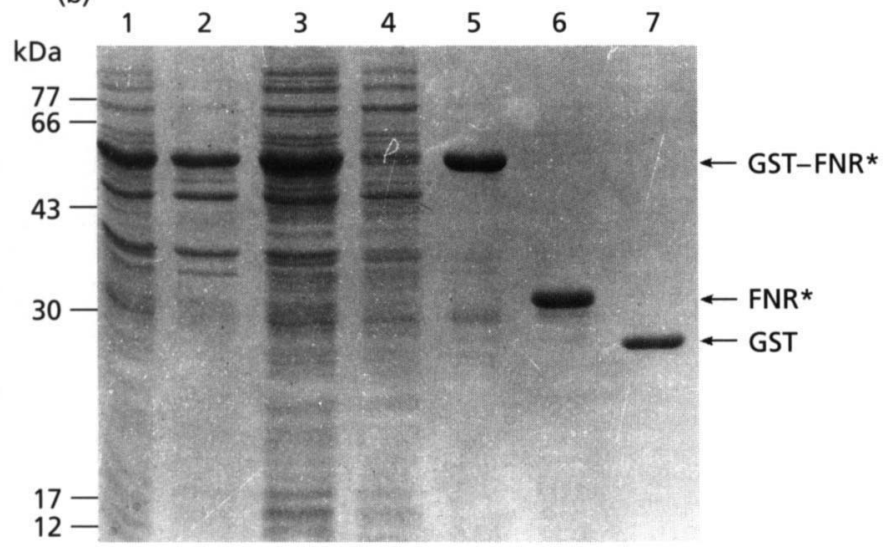

Fig. 2. Restriction map of the gst-fnr* expression plasmid (pGS771) and purification of the FNR* protein. (a) The gst and $\mathrm{fnr}^{*}$ coding regions are fused downstream of the IPTGregulated tac promoter. (b) SDS-PAGE analysis of samples taken during the purification of FNR* . Lanes ( $\mu$ g protein): 1 , total cell protein $(33) ; 2$, sedimentable fraction from crude extract (23); 3 , supernatant fraction of crude extract (52); 4, GSH-agarose column washings (12); 5 , GST-FNR* fusion, i.e. GSH eluate (6); 6 , purified FNR* $(5.5) ; 7$, purified GST $(4.5)$. The positions of the GST-FNR*, FNR* and GST proteins, and the molecular mass markers, are indicated.

Protein concentrations were estimated according to Bradford (1976) with bovine serum albumin as standard, and SDSPAGE was performed according to Laemmli (1970) with Coomassie brilliant blue staining. Western blotting was performed by standard procedures using anti-FNR serum. The iron content of FNR* was estimated chemically after separation from unincorporated iron by chromatography on Sephadex G25 as previously described (Green et al., 1991). Acid-labile sulphide was measured according to Beinert (1983). A Bioprofil image analyser (Vilber-Lourmat) was used for quantitative densitometric analysis of autoradiograms.

The $\alpha$-subunit of RNAP was purified according to Igarashi $\&$ Ishihama (1991) from a genetically amplified source, BL21( $\lambda$ DE3)(pGEMAX185), kindly supplied by A. Ishihama, National Institute of Genetics, Mishima, Japan, except that DE52 chromatography was replaced by separation on BioScale $Q$ (Bio-Rad) using a BioLogic workstation.

Molecular-genetic methods. Standard methods were used for DNA isolation, purification and manipulation (Sambrook et al., 1989). Nucleotide sequencing was performed according to the manufacturer's instructions with a USB sequencing kit.
PCR amplifications were carried out under standard conditions with $P f u$ polymerase (Stratagene) or Taq polymerase (Promega). The primers used to amplify the $f n r^{*}$ fragment from pFNRDA154 were S308, 5' -CGGGATCC $A T G^{\mathrm{G}}$ TCCCGGAAAAGCG-3' ( $f n r$ coordinates 511-537), and S167, 5'-ACAACTGTCAACGCAGTTTG-3' ( $f n r$ coordinates 1387-1407) (mismatched bases shown in superscript letters). The former incorporates unique $\mathrm{Bam} \mathrm{HI}$ and $\mathrm{Ncol}$ restriction sites to facilitate subcloning during the construction of pGS771.

The Altered Sites in vitro Mutagenesis System (Promega) was used with uracil-containing template DNA from pGS828, a derivative of pALTER-EX1, to direct specific substitutions in the FNR-sites of Pndh (Fig. 1b). Three phosphorylated primers were used simultaneously to make the desired substitutions and at the same time eliminate or repair the respective tet or bla genes of the vector.

For gel retardation and DNase I footprinting analyses, wildtype and altered or truncated $n d h$ promoters contained in the 458 bp EcoRI-HindIII $(-259$ to +162$)$ or 285 bp HpaIIHindIII ( -90 to +162 ) fragments were obtained from pGS418 and its derivatives (pGS832-pGS834), were end-labelled with $\left[\gamma^{-32} \mathrm{P}\right]$ ATP [3000 Ci mmol ${ }^{-1}$ (111 TBq mmol $\left.{ }^{-1}\right)$; Amersham] on the lower (HindIII site), upper (EcoRI site), or both strands according to Sambrook et al. (1989). The procedures for gel retardation and DNase I footprinting have been described previously (Green \& Guest, 1994): Maxam and Gilbert G tracks provided corresponding calibrations in the latter. Gels were dried and autoradiographed at $-70^{\circ} \mathrm{C}$. RNAP saturated with $\sigma^{70}$ was obtained from Pharmacia.

\section{RESULTS}

\section{Binding of FNR * to the $n d h$ promoter}

The FNR* protein containing a D154A substitution in the putative dimer interface was used to investigate the mechanism of FNR-mediated repression of $n d h$ gene expression. It was chosen because the substitution enhances dimer stability, thus providing a form of FNR that by-passes the need for allosteric activation via the highly unstable [4Fe-4S] clusters, and is sufficiently active to allow gel retardation analysis to be done under aerobic conditions (Kiley \& Reznikoff, 1991; Lazazzera et al., 1993). The FNR* protein was obtained by enzymic cleavage of an amplified GST-FNR" fusion protein (Fig. 2 ; see Methods). Its DNA-binding affinity in footprinting reactions was approximately fourfold higher than comparable samples of wild-type FNR. Gel retardation analysis with FNR* supported previous conclusions from DNase I footprinting with FNR that there are two FNR-binding sites in the $n d h$ promoter region (Fig. 3a). Both sites were fully occupied when the FNR * concentration exceeded $500 \mathrm{nM}$ and the concentration of FNR" giving $50 \%$ retardation of $n d h$ DNA $\left(K_{\mathrm{d}}\right)$ was $250 \mathrm{nM}$. Removal of the upstream site, FNR II, led to the formation of a single FNR*: $n d h$ complex and a lowering of the $K_{\mathrm{d}}$ to $140 \mathrm{nM}$ (Fig. 3b). This confirms that FNR has a higher affinity for the conserved consensus in FNR I than the divergent site in FNR II. In similar experiments with added RNAP, the formation of a highly retarded complex confirmed that RNAP and FNR* (like FNR) can simultaneously interact with the $n d h$ promoter (Fig. 3c). Further confirmation that the regulator and polymerase can bind simultaneously was 
(a)

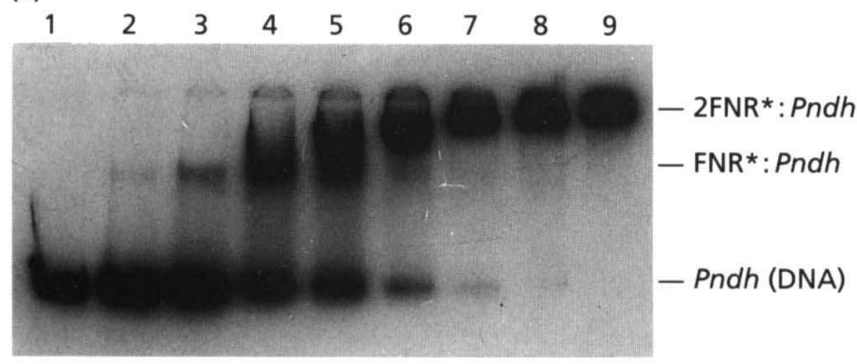

(b)

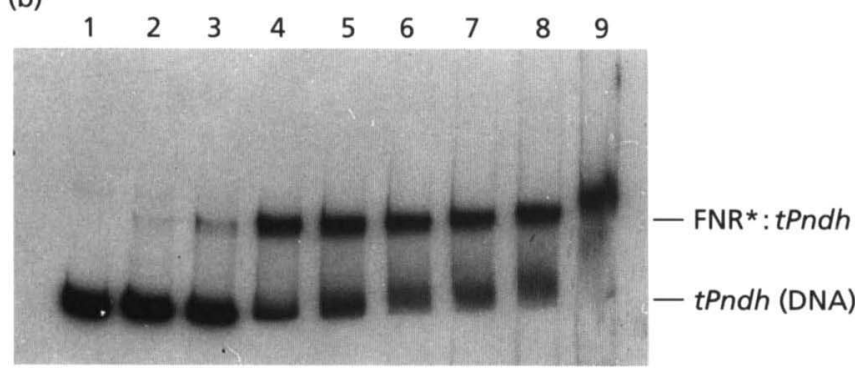

(c)

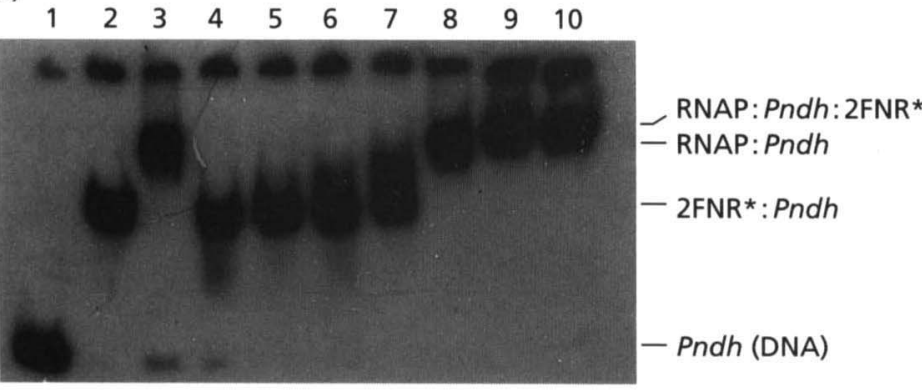

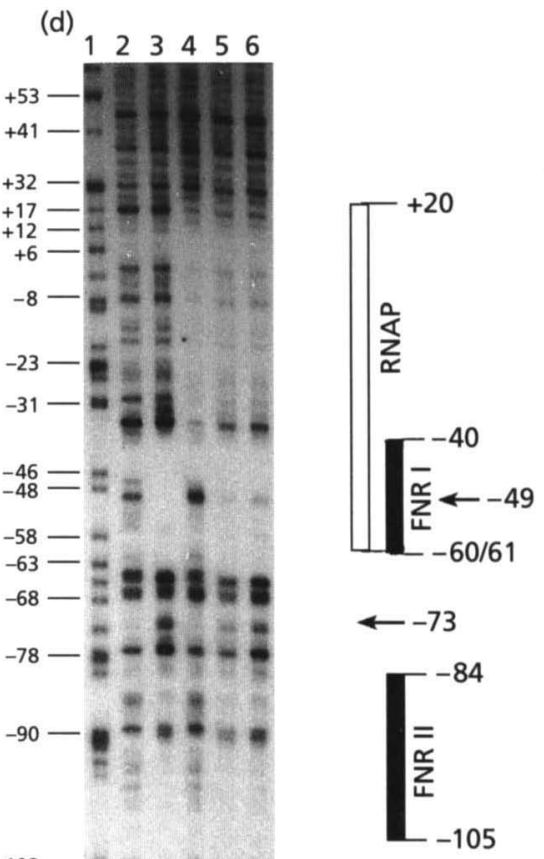

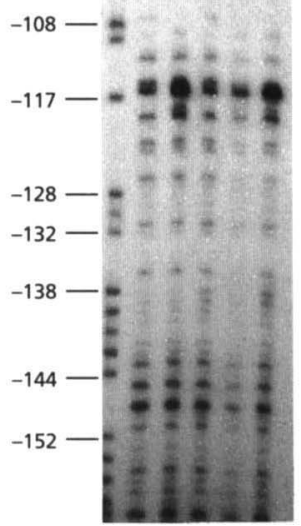

Fig. 3. Formation of an RNAP:FNR*:Pndh ternary complex in vitro. Gel retardation analysis of FNR* interactions with wild-type (a) and truncated (b) ndh promoters. Fragments labelled at both ends $(0.2 \mathrm{nM}$, final concentration) were incubated for $5 \mathrm{~min}$ at $37^{\circ} \mathrm{C}$ with increasing concentrations of FNR* and fractionated immediately in $5 \%$ polyacrylamide gel. Lanes: 1, no FNR*; 2-9, 25, 50, 100, 125, 188, 250, 500 and $1000 \mathrm{nM}$ FNR* dimer, respectively. (c) Effects of adding

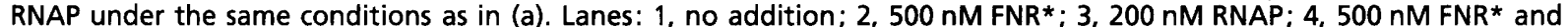
$10 \mathrm{nM}$ RNAP; 5, $500 \mathrm{nM}$ FNR* and $20 \mathrm{nM}$ RNAP; 6, $500 \mathrm{nM}$ FNR* and $40 \mathrm{nM}$ RNAP; 7, $500 \mathrm{nM}$ FNR* and $80 \mathrm{nM}$ RNAP; 8 , $500 \mathrm{nM} \mathrm{FNR}^{*}$ and $100 \mathrm{nM}$ RNAP; 9, $500 \mathrm{nM}$ FNR* and $150 \mathrm{nM}$ RNAP; $10,500 \mathrm{nM}$ FNR* and $200 \mathrm{nM}$ RNAP. (d) DNase I footprints of FNR* and RNAP at the ndh promoter. The ndh promoter fragment $(1.5 \mathrm{nM})$ labelled on the upper strand was incubated with no protein (lane 2) or with 1000 nM FNR* (lane 3); 500 nM RNAP (lane 4); 1000 nM FNR ${ }^{\star}$ and 500 nM RNAP (lanes 5 and 6), followed in each case by digestion with 1 unit of DNase I. Lane 1: Maxam-Gilbert G track of the same DNA fragment ( $2.7 \mathrm{nM})$. The regions protected by FNR* (filled boxes) and RNAP (open box) are indicated.

obtained from DNase I footprints of the ternary complex (Fig. 3d). On its own, FNR* protected two regions of the $n d h$ promoter $(-61$ to -40 and -105 to -84$)$ corresponding to the FNR-I- and FNR-II-sites identified previously (Sharrocks et al., 1991; Green et al., 1993), and generated a hypersensitive site at an intermediate position, -73 (Fig. 3d). Likewise, RNAP alone protected from -60 to +20 and generated a hypersensitive site at -49 . However, when RNAP was add to the $2 F^{*}: n d h$ complex, two protected regions were detected: one extended from -61 to +20 , combining that of RNAP ( -38 to + 20) with FNR* at FNR I ( -61 to
$-38)$; and the other at -105 to -84 corresponded to FNR" bound at FNR II (Fig. 3, lanes 5 and 6). The loss of the RNAP-induced hypersensitive site at -49 and the reappearance of the hypersensitive site at -73 upon adding FNR" indicates that FNR * changes the upstream region of the RNAP footprint and induces distortion in the DNA between the two FNR-binding sites. Not only do these patterns show that FNR" and RNAP can simultaneously occupy the $n d h$ promoter, they also indicate that the upstream contacts between RNAP and $P n d h$ in the -60 to -38 region are prevented when FNR* is bound at FNR I. It is relevant that another 
(a)
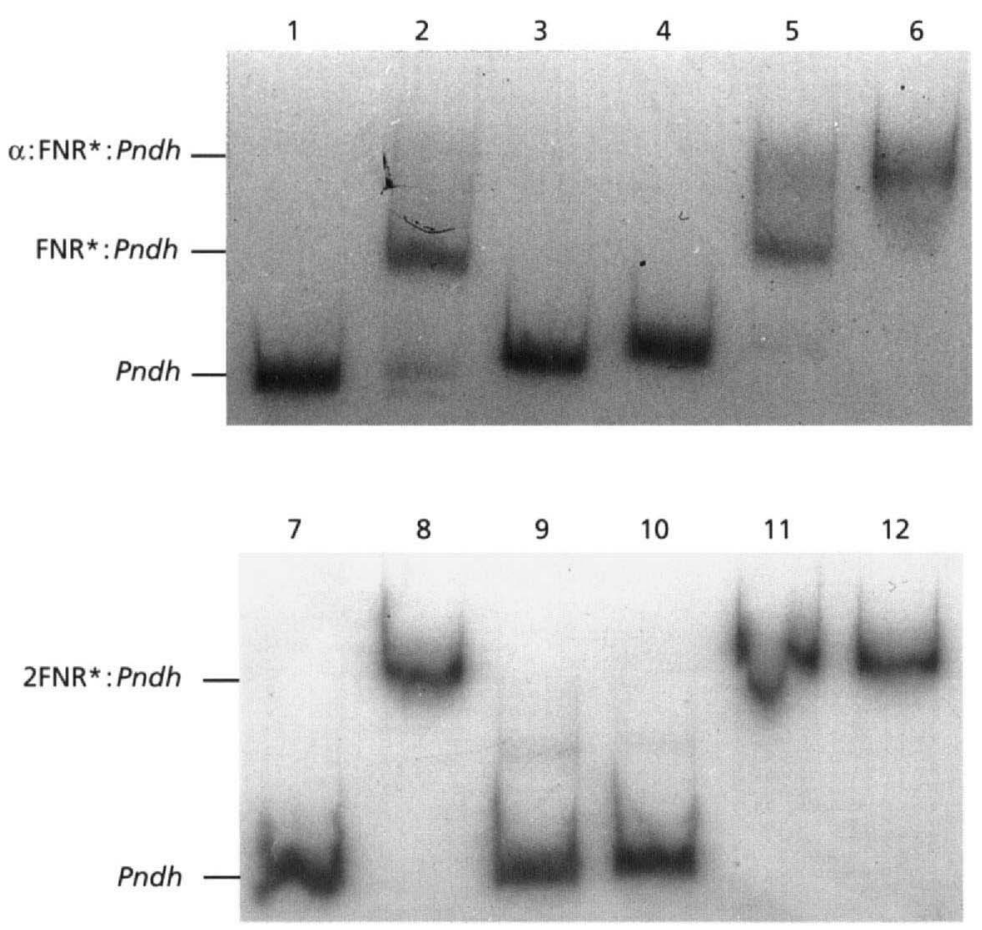

(c)

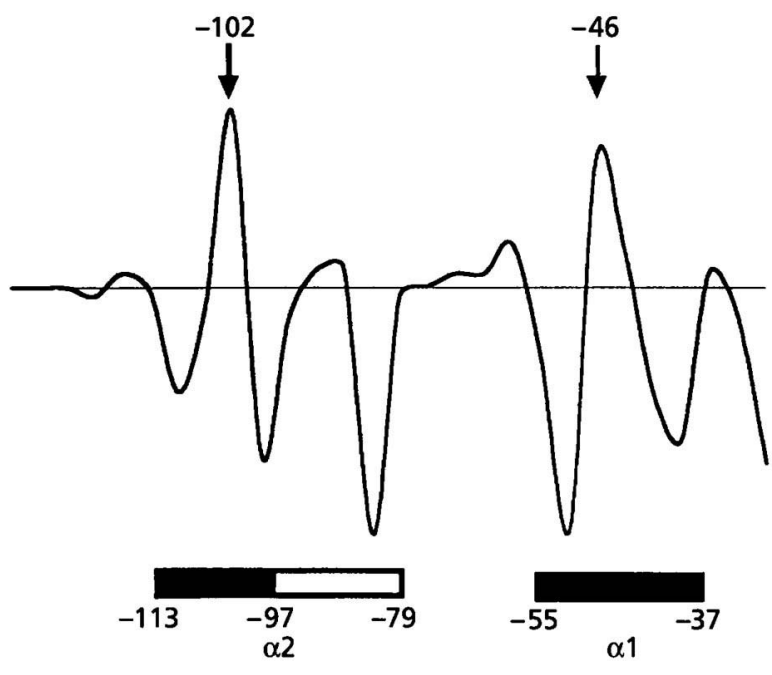

(b)

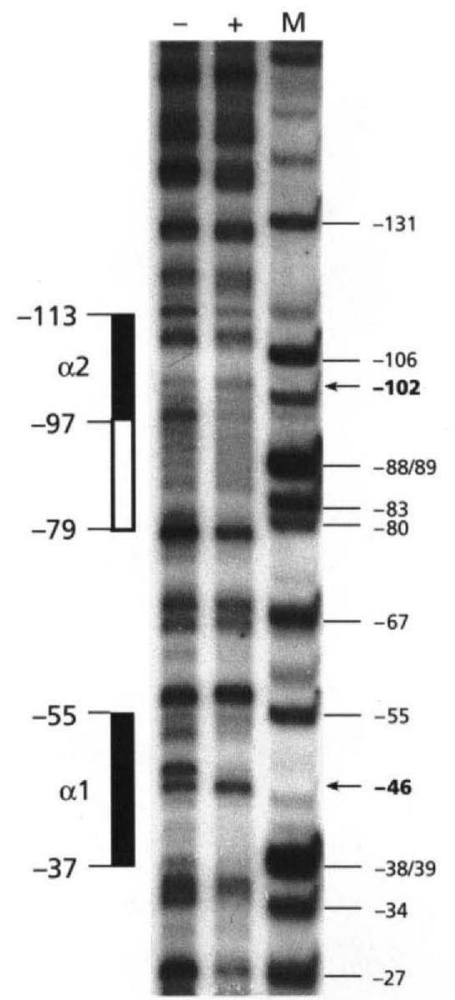

Fig. 4. Interactions of the RNAP $\alpha$-subunit and FNR* with the ndh promoter. (a) Gel retardation assays with end-labelled Pndh, FNR* and $\alpha$-subunit. Lanes ( $\mu$ M FNR* dimer or $\alpha$-subunit): 1, 7, no protein; 2, $\mathrm{FNR}^{*}(2) ; 3,9, \alpha(4) ; 4,10, \alpha(10) ; 5, \mathrm{FNR}^{*}(2)$ and $\alpha$ (4); 6, FNR* (2) and $\alpha(10) ; 8$, FNR $^{*}$ (4); 11, FNR* (4) and $\alpha(4) ; 12$, FNR* (4) and $\alpha(10)$. The positions of free DNA and retarded complexes are indicated. (b) DNase I footprinting of Pndh: $\alpha$-subunit binary complexes. DNase I digestion patterns for Pndh in the absence $(-)$ and presence $(+)$ of $\alpha$-subunit ( $83 \mu \mathrm{M}$ dimer) are aligned with a G-track calibration (M) obtained by DMS-piperidine hydrolysis of the same labelled fragment. (c) Densitometric difference profile for the $\alpha$-binding regions, track $(+)$ minus $(-)$ after normalizing in the unaffected upstream region. Values below the line denote protection whereas those above the line correspond to hypersensitive sites (arrowed).

FNR* protein is reported to bind as a monomer at a site in the hemA promoter TTGAT----cgCAt; Melville \& Gunsalus, 1996) that is similar to FNR II. However, even though FNR II has little more than one half-site, the protection patterns indicate that two FNR" subunits are bound. Close scrutiny of the hem $A$ footprint suggests that the same is true for its poor FNR-site.

\section{FNR and the $\alpha$-subunit of RNAP compete for overlapping binding sites in the $n d h$ promoter}

Because it appeared that FNR-mediated repression of $P n d h$ is not simply due to promoter occlusion, evidence was sought for interactions between FNR* and the $\alpha$ subunit of RNAP using gel retardation and footprinting analysis. Purified $\alpha$-subunit had a relatively low affinity for Pndh (Fig. 4a, lanes 3 and 4), but it was readily recruited to the $n d h$ promoter when FNR* occupied FNR I, the high-affinity site at -50.5 (Fig. 4 a, lanes 5 and 6). However, the $\alpha$-subunit was no longer recruited when both FNR-sites were occupied (Fig. 4a, lanes 11 and 12). This suggests that repression by FNR may require the disruption of essential contacts between the $\alpha$-subunit and Pndh.

DNase I footprints of the $\alpha$-subunit:Pndh complex revealed that $\alpha$ occupies two sites in the $n d h$ promoter: a site $(-55$ to -37$)$ which overlaps FNR I; and a weakly protected site $(-113$ to -98$)$ which overlaps FNR II (Fig. 4b). The protected regions were confirmed 


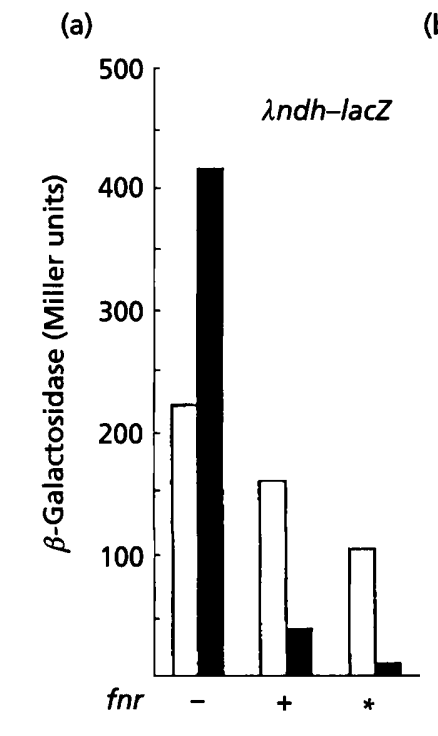

(b)

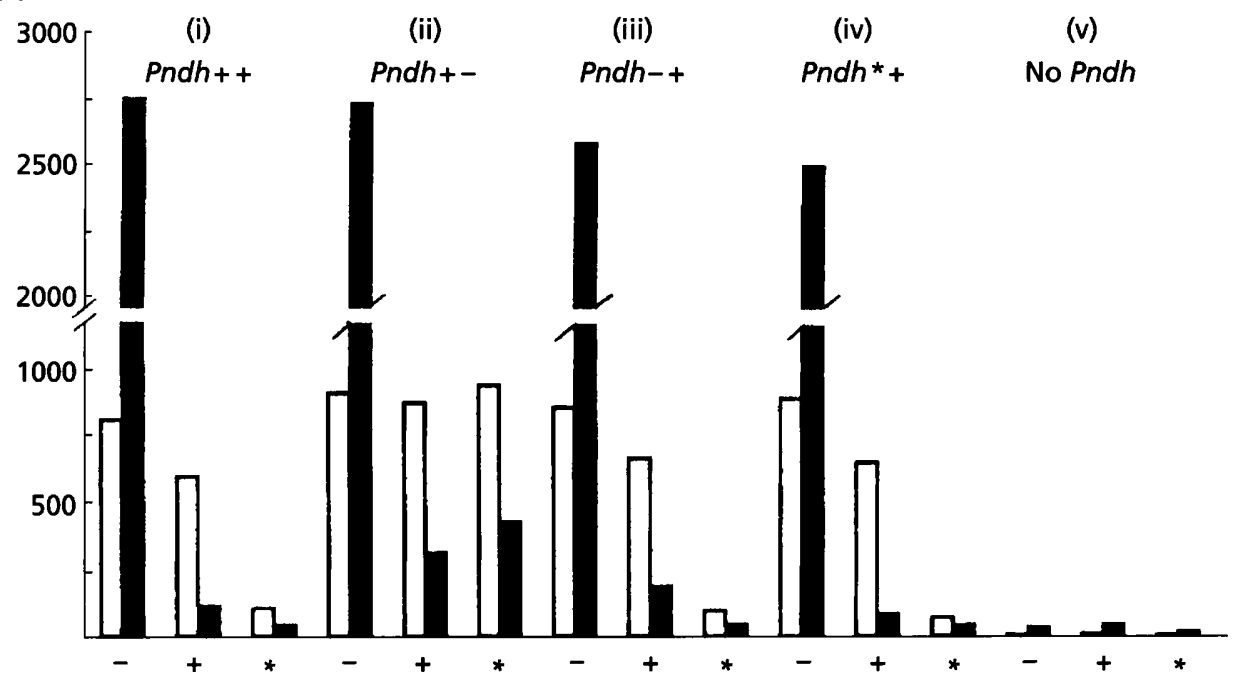

Fig. 5. Repression of $n d h$ gene expression in vivo requires both FNR sites. $\beta$-Galactosidase activities expressed from wildtype and altered ndh-lacZ fusions in analogous RK5279 ( $\Delta / a c$ fnr) transformants grown aerobically (open bars) or anaerobically (filled bars). (a) Transformants of a $\lambda$ ndh-lacZ monolysogen of RK5279 containing: -, pBR328 (vector control); +, pGS388 ( fnr $r^{+}$; or pGS1009 ( $\left.f n r^{*}\right)$. (b) Transformants of RK5279 containing: -, pUC18 (vector control); + , pGS366 ( fn $\left.r^{+}\right)$; or *, pGS998 ( fnr $\left.r^{\star}\right)$; and compatible low-copy pRW50 derivatives encoding ndh-lacZ operon fusions with wild-type or altered $n d h$ promoters [(i) Pndh ++ ; (ii) Pndh + - ; (iii) Pndh - + ; (iv) Pndh* +] or (v) no Pndh (pRW50).

by densitometric difference analyses: the binding-site profiles are similar and each contains a hypersensitive site, -46 and -102 (Fig. 4c). It is envisaged that the $\alpha-$ subunit is recruited to the weaker upstream location when FNR* is bound to the high-affinity FNR-I-site centred at -50.5 , and that $\alpha$-binding to its weaker upstream site is likewise prevented when FNR* is bound at the low-affinity FNR-II-site centred at -94.5 (Fig. 1a). By precluding interaction between the $\alpha$-subunit and $n d h$ promoter DNA, FNR* might thus allow the unrestrained $\alpha$-subunit to inhibit transcription activation.

\section{Aerobic repression of Pndh by FNR*}

The $f n r^{*}$ mutants were detected by virtue of their ability to activate, albeit to a limited extent, the aerobic expression of a narG-lacZ reporter fusion in vivo (Kiley \& Reznikoff, 1991). It was therefore of interest to test whether FNR* could likewise repress $n d h$ expression under aerobic conditions. Studies with a $\lambda n d h-l a c Z$ monolysogen of RK5279 ( $\Delta l a c f n r$ ) transformed with analogous $f n r, f n r^{*}$ or control plasmids, showed that FNR* partially represses $n d h$ expression under aerobic conditions (Fig. 5a). The degree of aerobic repression was significantly greater with FNR * than FNR, and $n d b$ expression was likewise more severely repressed by FNR* than FNR under anaerobic conditions (Fig. 5a). The anaerobic derepression of $n d h$ expression observed in the absence of FNR or FNR* (Fig. 5a) is mediated by the amino acid response regulator (Arr) which activates $n d h$ expression under these conditions (Spiro et al., 1989; Green \& Guest, 1994).

\section{Effects of altering the FNR-sites in the $n d h$ promoter}

In previous studies on the interaction between FNR and Pndh it was shown that the upstream FNR-II-site is needed for efficient FNR-mediated repression; the role of the higher affinity FNR-I-site was not defined (Green \& Guest, 1994). Here, site-directed mutagenesis was used to generate three $n d b$ promoter variants: $P n d h+-$, in which the relatively poor upstream FNRII-site was retained but FNR I was impaired by replacing the discriminatory $\mathbf{T}$ in each TTGAT half-site; $P n d b-+$, in which the discriminatory $\mathrm{T}$ in the consensus half-site of FNR II was substituted and the only conserved base in the other half-site (CCCGG) was altered, but FNR I was retained; and Pndh*+, in which FNR II was improved by replacing the poor halfsite by the consensus motif, and FNR I was unchanged (Fig. 1b).

Impairing the downstream FNR-I-site inhibited FNR* binding but a weak FNR*:Pndh +- retarded complex was formed due to the continued interaction of FNR* with FNR II (Fig. 6a ii). Protection at FNR II is evidenced by the hypersensitive site at -88 in the footprint (Fig. 6bii), consistent with the inherently low affinity of FNR II for FNR*. Although a FNR*: RNAP:Pnd $b+-$ ternary complex was formed, it contrasted with the wildtype complex insofar as the RNAP component of the footprint was not affected by FNR*, as indicated by the retention of the hypersensitive site at -49 (Fig. 6b). The corresponding $n d b-l a c Z$ fusion showed that $P n d h+-$ is still subject to anaerobic repression by FNR and FNR* in vivo despite the lack of interaction with 

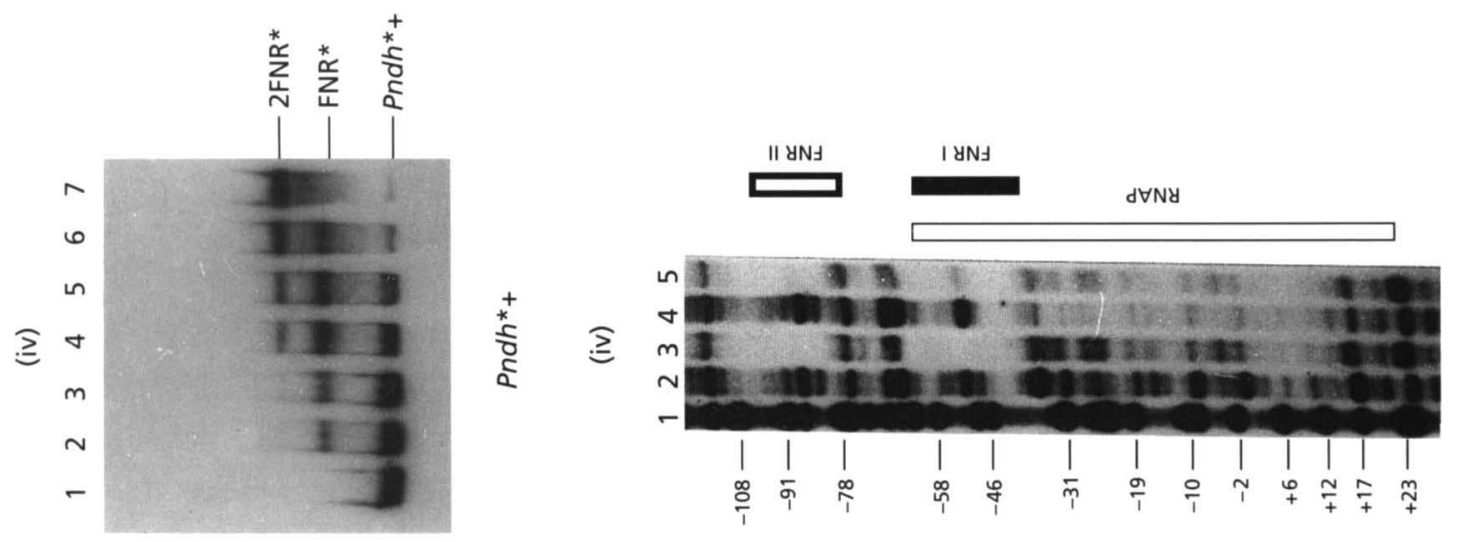
ভำ $+\because-\frac{0}{\pi}$ 홀

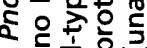

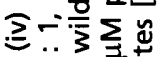
월

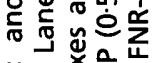
干* 1 恼

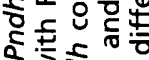

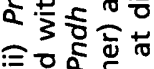
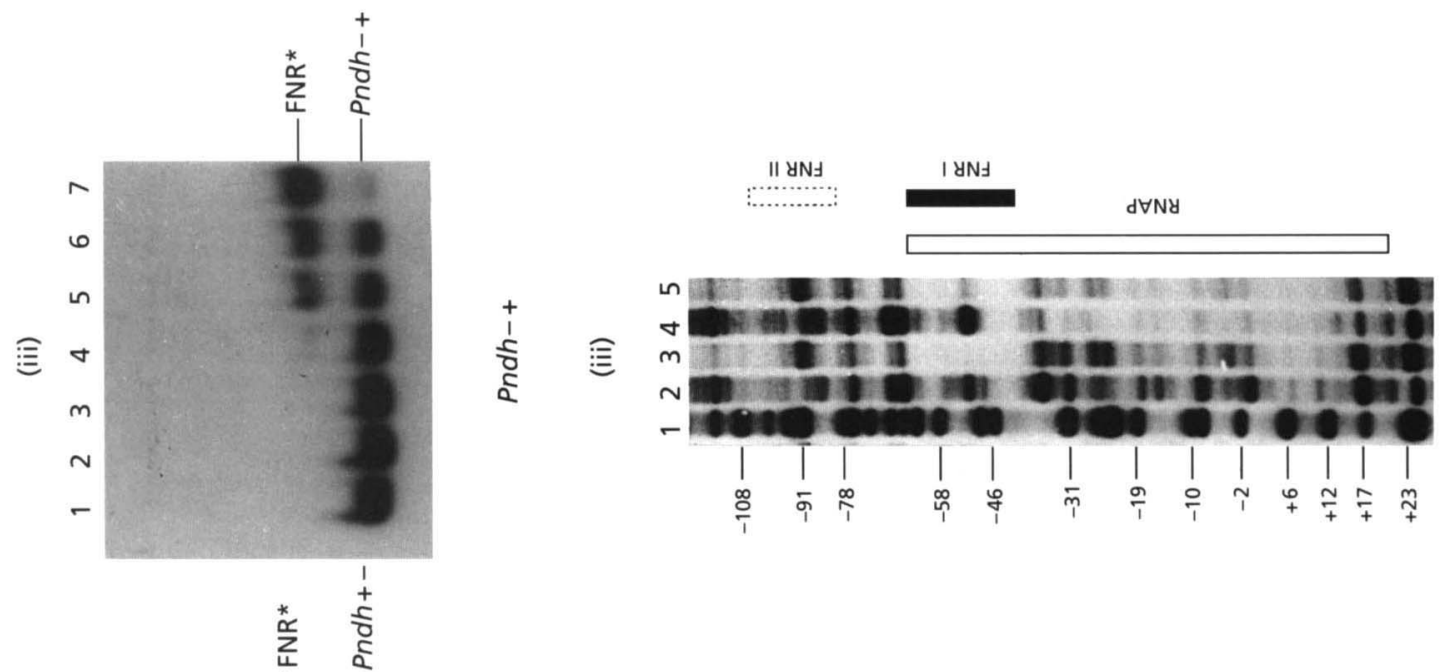

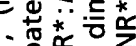

促

$+\mathrm{E}$

定.

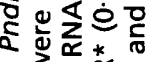

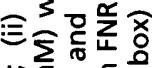

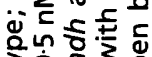
20종

은 한

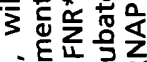

$+70$

$+20.5$

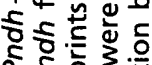

\& 5

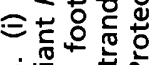

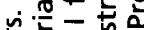

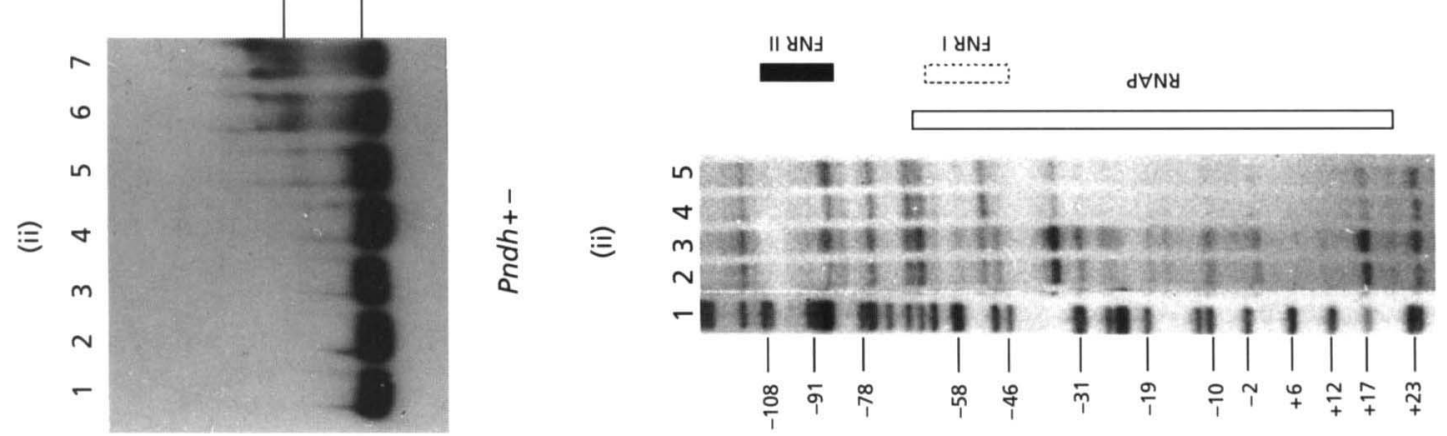

这

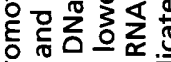

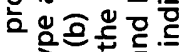

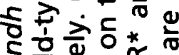

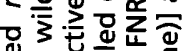

d。

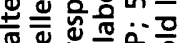

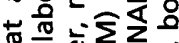

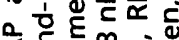

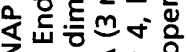
ख

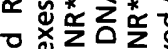

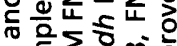
* हों

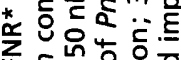

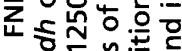

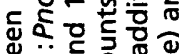
*

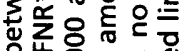
范응
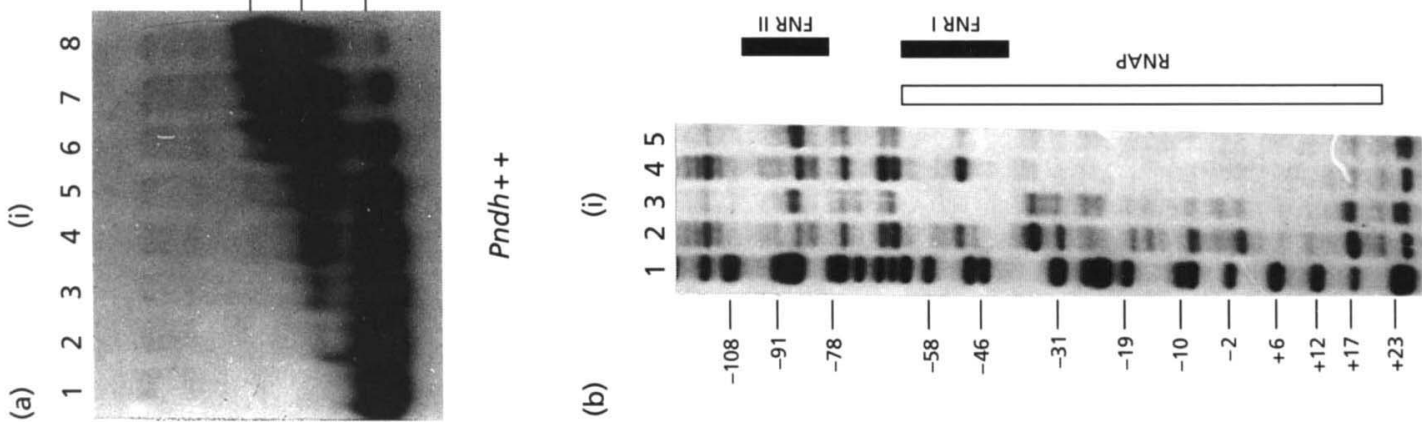

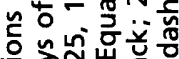

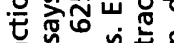

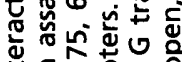
드의의 응 응 6 0 \%

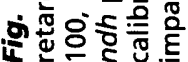


FNR I, although the degree of repression by FNR (or FNR*) was reduced from 7- (or 20-) fold for Pndh + + to 2.9- (or 2.2-) fold for $P n d h+-$, relative to the corresponding aerobic activities measured in the absence of FNR (Fig. 5b).

Impairing the poor upstream FNR-II-site produced a single $\mathrm{FNR}^{*}: P n d h-+$ retarded complex presumably with FNR* bound at the unaltered FNR-I-site (Fig. 6aiii), and a ternary complex with added RNAP (Fig. 6biii). The pattern of protection again indicates that FNR" prevents contact between RNAP and Pndh -+ at the upstream extremity of the RNAP component of the footprint, as was observed with Pndh ++ (Fig. 6b). The presence of the weakened FNRII-site in Pndh - + did not abolish anaerobic repression in vivo (Fig. 5b) although the presence of the hypersensitive site at -88 suggests that $\mathrm{FNR}^{*}$ may still interact to some extent at FNR II. Consistent with the impaired binding to $P n d h-+$, the degree of repression by FNR (or FNR *) in vivo was lowered to 4.4- (or 20-) fold at $P n d h-+$ compared with 7- (or 20-) at $P n d h++$. The degree of repression was also greater than the factor of 2.9 (or 2.2) observed at Pndh + - where FNR II is the only active FNR-binding site. The 20 -fold repression observed with FNR* probably corresponds to the maximum observable degree of repression.

Improving FNR II whilst retaining FNR I enhanced the binding affinity of FNR* for Pndh*+, as witnessed by the formation of retarded complexes at lower FNR* concentrations compared to Pndh ++ (Fig. 6a), and by the enhanced protection of FNR II in DNase I footprints (Fig. 6b). Interestingly, the footprint of the improved FNR II resembled that of FNR I in lacking the hypersensitive base at -88 normally present in the unaltered FNR II footprint. This suggests that the DNA in this region adopts different conformations in the two $\mathrm{FNR}^{*}:$ Pndh complexes. Improving the upstream site was also accompanied by an increased degree of anaerobic repression in vivo, 10.3- (or 21-) fold by FNR (or FNR*) with Pndh* + compared to 7- (or 20-) fold with the unaltered promoter, relative to the corresponding aerobic activities measured in the absence of FNR (Fig. 5b).

\section{DISCUSSION}

The molecular mechanisms of transcription activation by members of the FNR-cAMP receptor protein (CRP) family of transcription regulators have been studied extensively and shown to depend on the formation of specific contacts between the regulator and RNAP which promote transcription initiation (Bell \& Busby, 1994; Wing et al., 1995; Guest et al., 1996; Busby \& Kolb, 1996). Far less is known about the mechanisms of FNRmediated transcription repression. Three genes whose anaerobic repression by FNR has been studied at the in vitro level are: $f n r$ and narX (Takahashi et al., 1994) and $n d h$ (Sharrocks et al., 1991; Green \& Guest, 1994). The promoter regions of each of these genes contain more than one FNR-site, the most upstream of which seems to play a crucial role in FNR-mediated repression. Thus it would appear that FNR-mediated repression may not simply involve competition between FNR and RNAP for overlapping binding sites (Green \& Guest, 1994; Guest et al., 1996). The current studies were simplified by using FNR* (FNR-D154A) protein, which unlike the wild-type protein, retains some activity under aerobic conditions, both in vivo and in vitro (Kiley \& Reznikoff, 1991; Lazazzera et al., 1993). This FNR variant, already known to activate nar $G$ expression aerobically (Kiley \& Reznikoff, 1991), has now been shown to repress $n d b$ expression under aerobic conditions. Studies with $n d b-$ lacZ fusions further showed that impairment of either of the upstream FNR-sites in the $n d h$ promoter (FNR II and FNR I) reduces the level of anaerobic repression. The results extend previous studies in which the importance of the far upstream site (FNR II) had been inferred from the complete loss of repression observed in vivo with a truncated promoter lacking FNR II, and from the sixfold higher FNR concentration needed to repress transcription in vitro from the truncated promoter relative to the intact promoter (Green \& Guest, 1994). The DNase I footprints with FNR* likewise confirmed that the bound regulator alters but does not prevent RNAP polymerase from interacting with the $n d h$ promoter. The C-terminal domain of the $\alpha$-subunit of RNAP $\left(\alpha_{\mathrm{CTD}}\right)$ is not required for RNAP assembly or catalytic activity, but it can increase promoter strength by binding upstream of the -35 element and it can also interact with transcription activators. The current work provides direct evidence for $\alpha$-subunit binding at two upstream sites in the $n d b$ promoter.

The view that the operator sites of global regulators occupy a wider variety of locations in negatively regulated promoters than in positively regulated promoters (Collado-Vides et al., 1991) is upheld for FNR where binding sites are centred at -50.5 and -94.5 in $n d h ;-0.5$ and -103 in $f n r ;-35.5$ in $\operatorname{sod} A$; and $-106 \cdot 5,-75 \cdot 5$ and $+107 \cdot 5$ in narX (Guest et al., 1996). Such diversity probably allows each promoter to be regulated to different extents, and this is supported by studies on the effects of repositioning the lac operator (Lanzer \& Bujard, 1988). The greatest degree of repression was observed when the operator was located between the -35 and -10 elements, such that repressor binding occludes both promoter elements. An intermediate degree of repression occurred when the operator overlapped both the -10 element and the transcription start point. Here the bound repressor occludes the initiation region but RNAP can still form potentially productive complexes by interacting with the -35 element. The weakest degree of repression was observed when the operator was placed immediately upstream of the -35 element. This is the least effective arrangement for preventing RNAP binding because it leaves exposed the critical -10 and initiation sites (Collado-Vides et al., 1991). The $n d h$ promoter most closely resembles the latter situation, particularly with respect to the weak repression observed when FNR I $(-50.5)$ is the only 


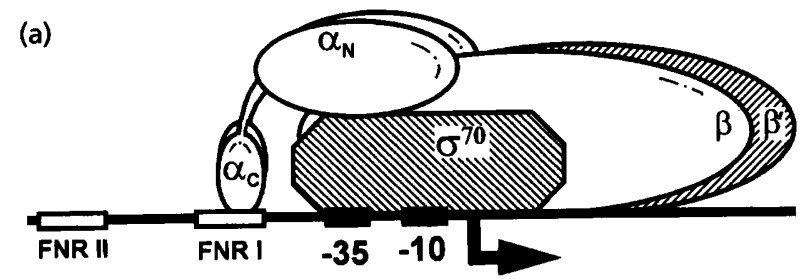

(b)
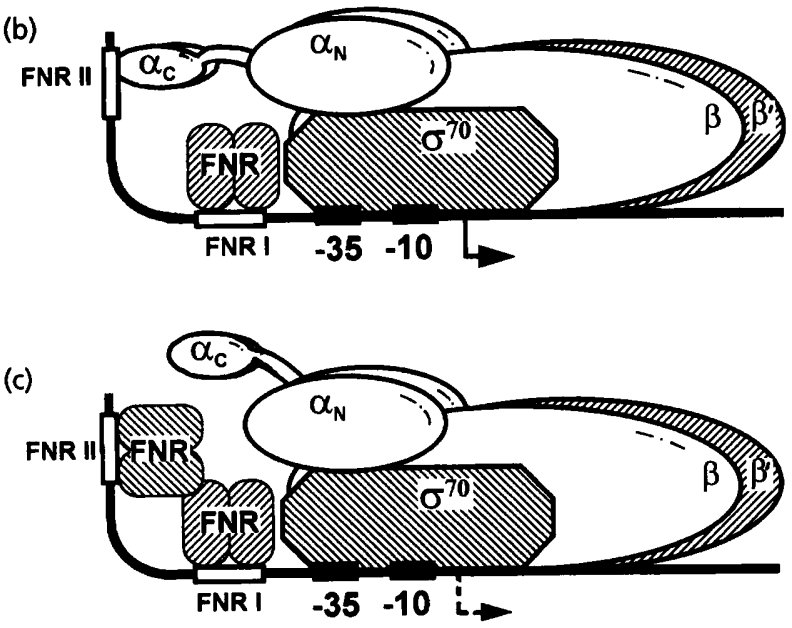

Fig. 7. Model for FNR-mediated repression of the ndh promoter. (a) In the absence of active FNR the $\alpha$-subunit of RNAP interacts with the DNA immediately upstream of the -35 element, allowing good transcription activation. (b) In the presence of low concentrations of active FNR, the high affinity FNR-I site is occupied and DNA-bending occurs such that the $\alpha$ subunit interacts with an upstream site, allowing a lower level of transcription activation. (c) When both FNR-sites are occupied, the C-terminal domain of the $\alpha$-subunit $\left(\alpha_{c}\right)$ is not anchored and inhibits transcription activation. The -35 and -10 elements (closed boxes); the primary and secondary FNRsites, FNR I at -50.5 and FNR II at -94.5 (open boxes); the Cterminal $\left(\alpha_{C}\right)$ and $N$-terminal $\left(\alpha_{N}\right)$ domains of the $\alpha$-subunit of RNAP; and the transcription start point (arrowed, the size of the arrow denoting relative rate of transcription initiation), are indicated.

functional FNR-site. The presence of tandem FNR-sites in the $n d h$ promoter also resembles the arrangement of CRP-sites in CytR-regulated promoters. Here, repression occurs when CytR binds to two bound CRP dimers and stabilizes the CRP-CytR-CRP-DNA complex solely by protein-protein interactions (Busby $\&$ Kolb, 1996). Such a mechanism is unlikely to operate at the $n d b$ promoter because FNR represses on its own.

A plausible model for FNR-mediated repression, accounting for the observed coexistence of FNR and RNAP at the repressed promoter, the presence of two $\alpha$ binding sites and the partial repression of $n d h$ expression from Pndh +- and Pndh- + , is shown in Fig. 7. During aerobic growth the inactive form of FNR has a low affinity for its targets in the $n d b$ promoter, so the -35 and -10 elements are freely accessible to RNAP (Fig. 7a). In this state, RNAP spans the -60 to +20 region (Fig. 3d) within which the $\alpha$-subunit interacts from -55 to -37 (Fig. $4 \mathrm{~b}$ ) presumably via $\alpha_{\text {CTD }}$, to form an RNAP: Pndh binary complex that can initiate transcription (Fig. 7a). Under microaerobic conditions, the increasing amounts of active FNR first occupy the high-affinity FNR-I-site and induce DNA-bending. This may in turn displace $\alpha_{\text {CTD }}$ to its weaker binding site $(-113$ to -98$)$ in the FNR II region (Fig. 3d), thus forming a complex that could still initiate a limited amount of transcription (Fig. 7b). Then, under strictly anaerobic conditions, the amounts of active FNR should be sufficient to occupy both FNR-sites, thereby completely blocking access to the $\alpha$-binding sites without preventing other interactions between RNAP and the ndh promoter (Fig. 7c). The unbound or 'orphaned' $\alpha_{\text {CTD }}$ may then in turn inhibit transcription initiation by destabilizing RNAP : promoter interactions (Zhou et al., 1994). The coexistence of both repressor and RNAP in a repression complex is not without precedent because RNAP can form a ternary complex with DNA-bound LacI (Straney \& Crothers, 1987).

An alternative model, which takes account of the residual binding of FNR* at the impaired FNR II site in $P n d h-+$ (more apparent in footprinting than gel retardation; Fig. 6iii), likewise confers a key role in repression on the weaker regulator interaction at the upstream FNR-II-site. This would involve modifying the above model to indicate that transcription is unaffected when FNR is bound solely at FNR I (Fig. 7b). Although consistent with the abolition of repression observed in vivo when FNR II is deleted, it does not account for the intermediate level of repression observed in vitro when FNR II is removed by truncating the promoter fragment so as to exclude the possibility that an alternative $\alpha$-binding site is provided by the upstream DNA (Green \& Guest, 1994). According to the alternative model, it might be predicted that RNAP would be occluded from the promoter when FNR is bound at both sites. However, the current gel retardation and footprinting studies confirm that two regulator molecules can be bound without displacing RNAP from this promoter.

The preferred model shown in Fig. 7 establishes a direct link between the mechanisms of transcription activation and repression. A key component of transcription activation from class II CRP-dependent promoters is the formation of 'anti-inhibition' contacts between CRP and $\alpha_{\text {CTD }}$ in order to relieve the inhibitory effects of an otherwise unbound $\alpha_{\text {CTD }}$ (Zhou et al., 1994). The evidence for 'anti-inhibition' includes the suppression of some crp 'positive control' mutations that accompanies the removal of $\alpha_{\text {CTD }}$ (West et al., 1993) and the observation that deleting $\alpha_{\text {CTD }}$ has no adverse effects on transcription activation at CRP-dependent class II promoters (Igarashi et al., 1991; Kolb et al., 1993). In the case of FNR-mediated $n d h$ repression it would appear that FNR prevents $\alpha_{\text {CTD }}$ from docking with the $n d h$ promoter. Presumably, due to specific architectural features of this promoter, particularly the locations of the FNR-sites, bound FNR cannot make the necessary 'anti-inhibition' contacts with the displaced or 'orphan' 
$\alpha_{\mathrm{CTD}}$, and transcription is repressed. So, whereas transcription activation requires suppression of the inhibitory effects of unbound $\alpha_{\text {CTD }}$ by contact with the regulator, repression can involve the generation of inhibitory $\alpha_{\text {CTD }}$ by regulator-mediated displacement from the promoter.

\section{ACKNOWLEDGEMENTS}

We thank Dr S. Busby for kindly providing some of the plasmids. We also thank Drs A. Irvine, S. Andrews and $M$. Quail for helpful advice. This work was supported by the BBSRC (J.R.G. \& J.G.), The Wellcome Trust (J.R.G.) and an Overseas Research Studentship (W.M.).

\section{REFERENCES}

Beinert, H. (1983). Semi-micro methods for the analysis of labile sulphide and of labile sulphide plus sulphane sulphur in ususually stable iron-sulphur proteins. Anal Biochem 131, 373-378.

Bell, A. \& Busby, S. (1994). Location and orientation of an activating region in the Escherichia coli transcription factor, FNR. Mol Microbiol 11, 383-390.

Bongaerts, J., Zoske, S., Weidner, U. \& Unden, G. (1995). Transcriptional regulation of the proton translocating NADH dehydrogenase genes (nuoA-N) of Escherichia coli by electron acceptors, electron donors and gene regulators. Mol Microbiol 16, 521-534.

Bradford, M. M. (1976). A rapid and sensitive method for the quantitation of microgram quantities of protein utilizing the principle of protein-dye binding. Anal Biochem 72, 248-254.

Busby, S. \& Kolb, A. (1996). The CAP modulon. In Regulation of Gene Expression in Escherichia coli, pp. 255-279. Edited by E. C. C. Lin \& A. S. Lynch. Austin, Texas: R. G. Lamdes.

Calhoun, M. W. \& Gennis, R. B. (1993). Demonstration of separate genetic loci encoding distinct membrane bound respiratory $\mathrm{NADH}$ dehydrogenases in Escherichia coli. J Bacteriol 175, 3013-3019.

Calhoun, M. W., Oden, K. L., Gennis, R. B., Teixeira de Mattos, M. J. \& Neijssel, O. M. (1993). Energetic efficiency of Escherichia coli: effects of mutations in components of the aerobic respiratory chain. J Bacteriol 175, 3020-3025.

Collado-Vides, J., Magasanik, B. \& Gralla, J. (1991). Control site location and transcriptional regulation in Escherichia coli. Microbiol Rev 55, 371-394.

Green, J. \& Guest, J. R. (1994). Regulation of transcription at the $n d h$ promoter of Escherichia coli by FNR and novel factors. Mol Microbiol 12, 433-444.

Green, J., Trageser, M., Six, S., Unden, G. \& Guest, J. R. (1991). Characterization of the FNR protein of Escherichia coli, an ironbinding transcriptional regulator. Proc R Soc Lond Ser Biol Sci 224, 137-144.

Green, J., Sharrocks, A. D., Green, B., Geisow, M. \& Guest, J. R. (1993). Properties of FNR proteins substituted at each of the five cysteine residues. Mol Microbiol 8, 61-68.

Green, J., Bennett, B., Jordan, P., Ralph, E. T., Thomson, A. J. \& Guest, J. R. (1996a). Reconstitution of the [4Fe-4S] cluster in FNR and demonstration of the aerobic-anaerobic transcription switch in vitro. Biochem J 316, 887-892.

Green, J., Irvine, A. S., Meng, W. \& Guest, J. R. (1996b). FNR-DNA interactions at natural and semi-synthetic promoters. Mol Microbiol 19, 125-137.

Guan, K. L. \& Dixon, J. E. (1991). Eukaryotic proteins expressed in
Escherichia coli: an improved thrombin cleavage and purification procedure of fusion proteins with glutathione S-transferase. Anal Biochem 192, 262-267.

Guest, J. R., Green, J., Irvine, A. S. \& Spiro, S. (1996). The FNR modulon and FNR-regulated gene expression. In Regulation of Gene Expression in Escherichia coli, pp. 317-342. Edited by E. C. C. Lin \& A. S. Lynch. Austin, Texas: R. G. Landes.

Hanahan, D. (1983). Studies on transformation of Escherichia coli with plasmids. $J$ Mol Biol 166, 557-580.

Hayashi, M., Miyoshi, T., Takashina, S. \& Unemoto, T. (1989). Purification of NADH-ferricyanide dehydrogenase and NADHquinone reductase from Escherichia coli membranes and their roles in the respiratory chain. Biochim Biophys Acta 977, 62-69.

Igarashi, K. \& Ishihama, A. (1991). Bipartite map of the E. coli RNA polymerase $\alpha$ subunit : involvement of the $C$-terminal region in transcription activation by cAMP-CRP. Cell 65, 1015-1022.

Igarashi, K., Hanamura, A., Makino, K., Aiba, H., Mizuno, T., Nakata, A. \& Ishihama, A. (1991). Functional map of the alpha subunit of Escherichia coli RNA polymerase: two modes of transcription activation by positive factors. Proc Natl Acad Sci USA 88, 8958-8962.

Khoroshilova, N., Beinert, H. \& Kiley, P. (1995). Association of a polynuclear iron-sulfur center with a mutant FNR protein enhances DNA-binding. Proc Natl Acad Sci USA 92, 2499-2505.

Kiley, P. J. \& Reznikoff, W. S. (1991). Fnr mutants that activate gene expression in the presence of oxygen. J Bacteriol 173, 16-22.

Kolb, A., Igarashi, K., Ishihama, A., Lavigne, M., Buckle, M. \& Buc, H. (1993). E. coli RNA polymerase, deleted in the C-terminal part of its alpha subunit, interacts differently with the cAMP-CRP complex at the lacP1 and the galP1 promoter. Nucleic Acids Res 21, 319-326.

Kunkel, T. A., Roberts, J. D. \& Zakour, R. A. (1987). Rapid and efficient site-specific mutagenesis without phenotypic selection. Methods Enzymol 154, 367-382.

Laemmli, U. K. (1970). Cleavage of structural proteins during the assembly of the head of bacteriophage T4. Nature 227, 680-685.

Lanzer, M. \& Bujard, H. (1988). Promoters largely determine the efficiency of repressor action. Proc Natl Acad Sci USA 85, 8973-8977.

Lazazzera, B. A., Bates, D. M. \& Kiley, P. (1993). The activity of the Escherichia coli transcription factor FNR is regulated by a change in oligomeric state. Genes Dev 7, 1993-2005.

Lazazzera, B. A., Beinert, H., Khoroshilova, N., Kennedy, M. C. \& Kiley, P. (1996). DNA binding and dimerization of the $\mathrm{Fe}-\mathrm{S}$ containing FNR protein from Escherichia coli are regulated by oxygen. J Biol Chem 271, 2762-2768.

Lodge, J., Fear, J., Busby, S., Gunasekaran, P. \& Kamini, N. R. (1992). Broad host range plasmids carrying the Escherichia coli lactose and galactose operons. FEMS Microbiol Lett 95, 271-276.

Matsushita, K., Ohnishi, T. \& Kaback, H. R. (1987). NADHubiquinone oxidoreductases of the Escherichia coli aerobic respiratory chain. Biochemistry 26, 7732-7737.

Melville, S. B. \& Gunsalus, R. R. (1996). Isolation of an oxygensensitive FNR protein of Escherichia coli: interaction at activator and repressor sites of FNR-controlled genes. Proc Natl Acad Sci USA 93, 1226-1231.

Miller, J. H. (1972). Experiments in Molecular Genetics. Cold Spring Harbor, NY: Cold Spring Harbor Laboratory.

Sambrook, J., Frisch, E. F. \& Maniatis, T. (1989). Molecular Cloning: a Laboratory Manual, 2nd edn. Cold Spring Harbor, NY: Cold Spring Harbor Laboratory. 
Sharrocks, A. D., Green, J. \& Guest, J. R. (1990). In vivo and in vitro mutants of FNR, the anaerobic transcription regulator of E. coli. FEBS Lett 270, 119-122.

Sharrocks, A. D., Green, J. \& Guest, J. R. (1991). FNR activates and represses transcription in vitro. Proc R Soc Lond Ser B Biol Sci 245, 219-226.

Shaw, D. J. \& Guest, J. R. (1982). Amplification and product identification of the f $\mathrm{nr}$ gene of Escherichia coli. J Gen Microbiol 128, 2221-2228.

Spiro, S., Roberts, R. E. \& Guest, J. R. (1989). FNR-dependent repression of the $n d h$ gene of Escherichia coli and metal ion requirement for FNR regulated gene expression. Mol Microbiol 3, 601-608.

Straney, S. B. \& Crothers, D. M. (1987). Lac repressor is a transient gene-activating protein. Cell 51, 699-707.

Takahashi, K., Hattori, T., Nakianishi, T., Nohno, T., Fujita, N., Ishihama, A. \& Taniguchi, S. (1994). Repression of in vitro transcription of the Escherichia coli f $n$ r and narX genes by FNR protein. FEBS Lett 340, 59-64.

Weidner, U., Nehls, U., Schneider, R., Fecke, W., Leif, H., Schmiede, A., Friedrich, T., Zensen, R., Schulte, U., Ohnishi, T. \&
Weiss, H. (1992). Molecular genetic studies of complex I of Neurospora crassa, Aspergillus niger and Escherichia coli. Biochim Biophys Acta 1101, 177-180.

West, D., Williams, R., Rhodius, V., Bell, A., Sharma, N., Zou, C., Fujita, N., Ishihama, A. \& Busby, S. (1993). Interactions between the Escherichia coli cyclic AMP receptor protein and RNA polymerase at class II promoters. Mol Microbiol 10, 789-797.

Wing, H., Williams، S. M. \& Busby, S. J.W. (1995). Spacing requirements for transcription activation by Escherichia coli FNR protein. J Bacteriol 177, 6704-6710.

Young, I. G., Rogers, B. L., Campbell, H. D., Jaworowski, A. \& Shaw, D. D. (1981). Nucleotide sequence for the respiratory NADH dehydrogenase of Escherichia coli. Eur J Biochem 116, 165-170.

Zhou, Y., Pendergrast, P. S., Bell, A., Williams, R., Busby, S. \& Ebright, R. H. (1994). The functional subunit of a dimeric transcription activator protein depends on promoter architecture. EMBO J 13, 4549-4557.

Received 7 November 1996; revised 20 December 1996; accepted 24 December 1996. 